\title{
Stunting and 'overweight' in the WHO Child Growth Standards - malnutrition among children in a poor area of China
}

\author{
Xiaoli Wang ${ }^{1}$, Bengt Höjer ${ }^{2}$, Sufang Guo ${ }^{3}$, Shusheng Luo' ${ }^{1}$, Wenyuan Zhou' ${ }^{1}$ and \\ Yan Wang ${ }^{1, *}$ \\ 'Division of Maternal and Child Health, School of Public Health, Peking University Health Science Center, \\ 38 Xueyuan Road, Haidian District, Beijing 100083, People's Republic of China: ${ }^{2}$ Division of International \\ Health (IHCAR), Department of Public Health Sciences, Karolinska Institutet, Stockholm, Sweden: ${ }^{3}$ Health \& \\ Nutrition, UNICEF Office for China, Beijing, People's Republic of China
}

Submitted 8 October 2008: Accepted 5 June 2009: First published online 6 August 2009

\begin{abstract}
Objective: The aims of the present paper were to assess the nutritional status of children under 5 years old using the 2006 WHO Child Growth Standards ('the WHO standards') and to compare the results with those obtained using the National Center for Health Statistics/WHO international growth reference ('the NCHS reference').

Design: This was a community-based cross-sectional survey. The WHO standards were used to calculate $Z$-scores of height-for-age (HAZ), weight-for-age (WAZ), weight-for-height (WHZ) and BMI-for-age (BMIZ).

Setting: Fifty counties of thirteen mid-western provinces, China.

Subjects: A total 8041 children aged $<5$ years were measured during a 2-month period from August to October 2006.

Results: The prevalence of stunting, underweight and wasting were $30 \cdot 2 \%, 10 \cdot 2 \%$ and $2.9 \%$, respectively. The prevalence of overweight and the possible risk of overweight were as high as $4 \cdot 1 \%$ and $16 \cdot 8 \%$. Further analysis among the children with possible risk of overweight found that the percentage of stunting $(\mathrm{HAZ}<$ -2) was $57 \cdot 6 \%$, the percentage with $-2 \leq \mathrm{HAZ} \leq 2$ was $41.0 \%$ and the percentage with HAZ $>2$ was only $1 \cdot 4 \%$. The prevalence of stunting was $21.9 \%$ and of underweight was $12 \cdot 7 \%$ by the NCHS reference.

Conclusions: Stunting was the most serious problem that was impeding child growth and development. The high rate of 'overweight' was a false impression, the truth being 'stunting overweight', and the way to solve it should be to increase protein and other nutrients in the diet at an early age.
\end{abstract}

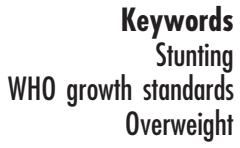

With the rapid growth of the national economy during the past several decades, the nutritional status of the Chinese people has improved greatly ${ }^{(1)}$. However, there are huge differences between urban and rural areas and the development of western areas has lagged behind that of eastern areas for several decades ${ }^{(2,3)}$. The average annual income per capita was \$US 249 in western areas, much lower than the national average annual income per rural resident in 2005, which was \$US $407^{(4)}$. Disparities also exist in the nutritional status of children. One survey stated the prevalence of underweight among children $<5$ years of age to be $1.8 \%$ in urban areas and $8.6 \%$ in rural areas, with corresponding stunting prevalence of $2.5 \%$ and $13 \cdot 1 \%{ }^{(5)}$. In another study the prevalence of stunting and underweight among children $<3$ years of age living in western areas was found to be $24.0 \%$ and $22 \cdot 4 \%$, respectively ${ }^{(6)}$. This indicates that malnutrition in poor rural areas is still a serious problem.

To improve child nutrition in western areas, the Chinese Ministry of Health and UNICEF are implementing a 'Mother and Baby Package Project' in the fifty counties of thirteen mid-western provinces in China during 2006 to 2010. In preparing for the evaluation of the interventions, a baseline survey focusing on child growth and development was conducted in the project area during a 2-month period from August to October 2006.

For nearly three decades, the international growth reference of the National Center for Health Statistics/WHO ('the NCHS reference') has been widely used to assess malnutrition $^{(7)}$, as recommended by WHO. The limitations 
of the NCHS reference have been documented by many researchers $^{(8-10)}$. Recognizing the shortcomings of the NCHS reference as an international growth reference, in 1994 the WHO began planning for new references that reflect child growth in all countries and do not simply describe children's growth at a particular time and place $^{(11,12)}$. In 2006, the WHO Child Growth Standards ('the WHO standards') were developed by the WHO Multicentre Growth Reference Study (MGRS) ${ }^{(13)}$. Until now there have been few reports about child nutrition related to the new standards but such work is important, especially for developing countries and poor areas ${ }^{(14,15)}$.

The aims of the present study were: (i) to assess the nutritional status of children $<5$ years old in rural China using the WHO standards; and (ii) to compare the results with those obtained using the NCHS reference.

\section{Material and methods}

\section{Study area and population}

The study was a cross-sectional survey. The 'Mother and Baby Package Project' was conducted in fifty counties of thirteen mid-western provinces of China. The project covered a total population of about 20 million inhabitants, including a sample from the almost $1 \cdot 1$ million children aged $<5$ years. In the present survey we conducted anthropometric measurements for children $<5$ years of age and conducted face-to-face questionnaire interviews with the children's caregivers. At the same time, we also collected background information from the fifty counties and all sampled townships and villages. The questionnaire included social, economic and demographic data, especially the number of children aged $<5$ years in each family.

We used a three-stage stratified, randomized, non-probability (quota allocation of samples) sampling method. We planned to recruit 170 children aged $<5$ years from each county. Because of the low density of population, it was difficult to reach 170 in seven counties, all located in Tibet. Hence, the raw sample size had to be limited to sixty children in each of these counties. Figure 1 shows the sampling process.

Within each county, all townships were ranked according to their hospital delivery rates; in the next step we divided them into three layers and kept almost the same number of towns in each layer. We then selected one township from each layer at random. In each sampled township, all villages were ranked according to their distance to the town government hall; then they were classified into three layers with the number of villages in each layer being approximately the same. Finally, we

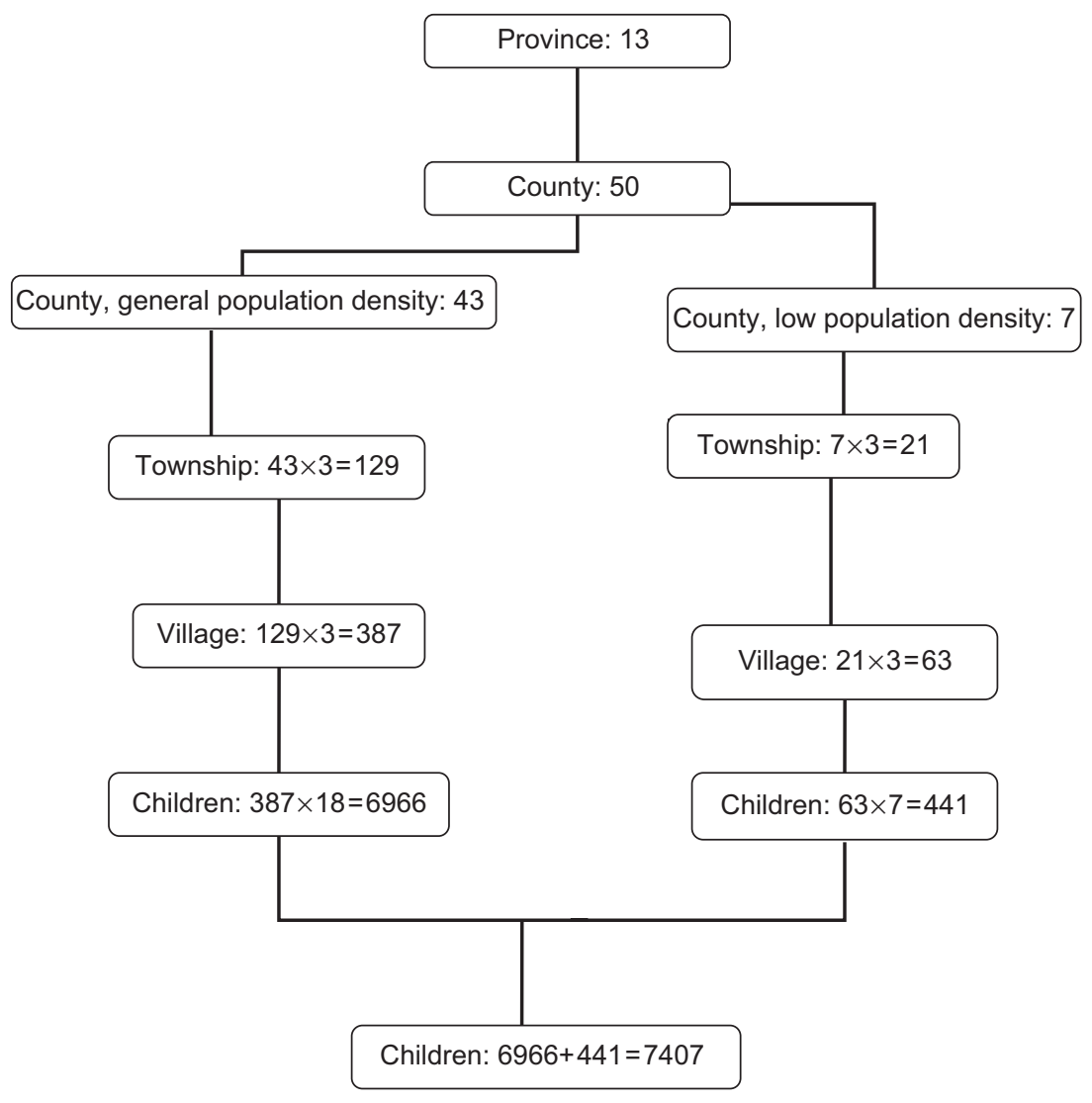

Fig. 1 The sampling process 
randomly selected one village from each layer. In total, fifty sampled counties including 150 sampled townships and 450 villages were included. Within this frame, 7407 children aged $<5$ years should be investigated (Fig. 1). Actually, a total of 8041 children were investigated and their height and weight were measured.

\section{Antbropometry}

Information, including the child's age, sex and other data, was obtained by interviewing the caregivers. Anthropometric measurements, including height and weight, were used to assess the nutritional status. Recumbent length of all children was assessed using a standard calibrated board accurate to the nearest $0 \cdot 001 \mathrm{~m}$ (model WB-B; Changzhou Wujin Company Measuring Factory, Changzhou, China) and their weights were measured to the nearest $0 \cdot 1 \mathrm{~kg}$ with a standard calibrated balance scale (Bailida electronic scale; Wuxi Measurement Factory, Wuxi, China). We were especially concerned about getting instruments that were highly accurate and precise, yet portable and sturdy enough to enable them to be carried back and forth in the field. All study sites used identical measuring equipment, which was provided by UNICEF.

The data collection team came from the Division of Maternal and Child Health, School of Public Health of Peking University. The team was divided into ten couples, each couple being made up of one teacher and one graduate student. Before the field survey, all members received training according to training manuals so that they would be completely consistent. The training covered filling in the questionnaire, inquiry manner, equipment use and measurement criteria. Measurements were carried out based on the recommended standards for anthropometry described elsewhere ${ }^{(16)}$.

A pilot survey including sixty children was conducted in Xia County, Shanxi Province and Bishan County of Chongqing Province, separately, through which some problems were revealed in the questionnaires and measurements. An appropriate procedure for the field survey was elaborated based on the pilot study experiences.

\section{Statistical analyses}

The WHO standards were used to calculate Z-scores of height-for-age (HAZ), weight-for-age (WAZ), weightfor-height (WHZ) and BMI-for-age $(\mathrm{BMIZ})^{(13)}$. Z-scores were calculated using the WHO Anthro 2005 for Personal Computer Software for Assessing Growth and Development of the World's Children, version Beta (WHO, Geneva, Switzerland). According to recommendations, stunting was determined as $\mathrm{HAZ}<-2$, underweight as $\mathrm{WAZ}<-2$, wasting as $\mathrm{WHZ}<-2$, possible risk of overweight as $\mathrm{BMIZ}>1$ and overweight as BMIZ $>2^{(17,18)}$

The database was established using the Epi Info software package version 6 (Centers for Disease Control and Prevention, Atlanta, GA, USA) and duplication was adopted for data entry. Means, standard deviations and the respective $Z$-scores were calculated for all anthropometric variables. The prevalence of stunting, underweight, wasting and overweight/obesity was determined in relation to age, sex and area. Malnutrition and overweight/obesity rates were compared between groups using the $\chi^{2}$ test. The SPSS statistical software package version $13 \cdot 0$ (SPSS Inc., Chicago, IL, USA) was used for all analyses. In all analyses $P<0 \cdot 05$ was considered as statistically significant.

\section{Results}

\section{Sex and age of the children}

For all 8041 children, we enquired their dates of birth and their sex from caregivers and their weight and height were assessed.

Table 1 shows the children's sex and age. Boys constituted $55 \cdot 5 \%$ and girls $44 \cdot 5 \%$ of the children. The children's

Table 1 Prevalence of underweight, stunting and wasting, determined using the 2006 WHO Child Growth Standards, by sex and age group: children $<5$ years of age from thirteen rural mid-western provinces, China $(n 8041)$

\begin{tabular}{|c|c|c|c|c|c|c|c|}
\hline & \multirow[b]{2}{*}{$\%$} & \multicolumn{2}{|c|}{ Stunting } & \multicolumn{2}{|c|}{ Underweight } & \multicolumn{2}{|c|}{ Wasting } \\
\hline & & $\%$ & $95 \% \mathrm{Cl}$ & $\%$ & $95 \% \mathrm{Cl}$ & $\%$ & $95 \% \mathrm{Cl}$ \\
\hline \multicolumn{8}{|l|}{ Sex } \\
\hline Boys & $55 \cdot 5$ & $32 \cdot 2$ & $30 \cdot 76,33 \cdot 56$ & $10 \cdot 6$ & $9 \cdot 72,11 \cdot 57$ & $3 \cdot 1$ & $2 \cdot 62,3 \cdot 66$ \\
\hline Girls & $44 \cdot 5$ & $27 \cdot 8$ & $26 \cdot 33,29 \cdot 34$ & $9 \cdot 7$ & $8 \cdot 69,10 \cdot 67$ & $2 \cdot 6$ & $2 \cdot 04,3.09$ \\
\hline$P$ value & & \multicolumn{2}{|c|}{0.000} & \multirow{2}{*}{\multicolumn{2}{|c|}{0.159}} & \multirow{2}{*}{\multicolumn{2}{|c|}{$0 \cdot 117$}} \\
\hline \multicolumn{4}{|c|}{ Age (months) } & & & & \\
\hline $0-5$ & $5 \cdot 7$ & $18 \cdot 5$ & $14 \cdot 85,22 \cdot 05$ & $4 \cdot 2$ & $2 \cdot 38,6 \cdot 13$ & $3 \cdot 1$ & $1 \cdot 53,4 \cdot 77$ \\
\hline $6-11$ & $16 \cdot 0$ & $17 \cdot 9$ & $15 \cdot 83,20 \cdot 07$ & $8 \cdot 6$ & $7 \cdot 07,10 \cdot 17$ & $4 \cdot 9$ & $3 \cdot 69,6 \cdot 06$ \\
\hline $12-17$ & $12 \cdot 4$ & $22 \cdot 3$ & $19 \cdot 69,24 \cdot 91$ & $7 \cdot 2$ & $5 \cdot 54,8 \cdot 78$ & $4 \cdot 8$ & $3 \cdot 46,6 \cdot 12$ \\
\hline $18-23$ & $14 \cdot 4$ & $35 \cdot 9$ & $33 \cdot 14,38 \cdot 75$ & $12 \cdot 0$ & $10 \cdot 19,14 \cdot 00$ & $2 \cdot 0$ & $1 \cdot 22,2 \cdot 86$ \\
\hline $24-29$ & $11 \cdot 6$ & $34 \cdot 6$ & $31 \cdot 47,37 \cdot 72$ & $10 \cdot 1$ & $8 \cdot 13,12 \cdot 09$ & $1 \cdot 2$ & $0.49,1.90$ \\
\hline $30-35$ & $11 \cdot 5$ & $36 \cdot 5$ & $33 \cdot 35,39 \cdot 71$ & $9 \cdot 5$ & $7 \cdot 57,11 \cdot 44$ & $1 \cdot 6$ & $0 \cdot 72,2 \cdot 32$ \\
\hline $36-41$ & $8 \cdot 1$ & $35 \cdot 9$ & $32 \cdot 09,39 \cdot 67$ & $12 \cdot 6$ & $9 \cdot 90,15 \cdot 17$ & $3 \cdot 0$ & $1 \cdot 65,4 \cdot 33$ \\
\hline $42-47$ & $8 \cdot 3$ & $37 \cdot 1$ & $33 \cdot 30,40 \cdot 85$ & $11 \cdot 2$ & $8 \cdot 63,13.56$ & $2 \cdot 2$ & $1 \cdot 06,3 \cdot 34$ \\
\hline $48-53$ & $5 \cdot 7$ & $32 \cdot 2$ & $27 \cdot 84,36 \cdot 67$ & $11 \cdot 1$ & $8 \cdot 02,13.93$ & $0 \cdot 7$ & $0.00,1.53$ \\
\hline 54-59 & 5.9 & $39 \cdot 2$ & $34 \cdot 70,43 \cdot 86$ & $19 \cdot 2$ & $15 \cdot 55,22 \cdot 94$ & $4 \cdot 0$ & $2 \cdot 15,5 \cdot 75$ \\
\hline Total & $100 \cdot 0$ & $30 \cdot 2$ & $29 \cdot 22,31 \cdot 27$ & $10 \cdot 2$ & $9 \cdot 54,10 \cdot 89$ & $2 \cdot 9$ & $2 \cdot 51,3 \cdot 25$ \\
\hline
\end{tabular}


age ranged from 0 to 59 months, and they were divided into ten age groups. The proportion in each age group is shown in Table 1.

\section{Cbildren's Z-scores}

Table 2 gives means and standard deviations of HAZ, WAZ, WHZ and BMIZ for different age groups determined using the WHO standards. Compared with the standards, the distributions of HAZ in all age groups and WAZ in most age groups were shifted to the left significantly, the extent of shifting showing an average for HAZ of $-1 \cdot 33$ and for WAZ of $-0 \cdot 70$. Being different from HAZ and WAZ, however, the distributions of WHZ and BMIZ were shifted to the opposite direction (average $0 \cdot 06$ and $0 \cdot 20$, respectively). This indicated the length/ height of the children dropped far behind the criteria, while in contrast WHZ and BMIZ were above the criteria and it seemed the children were 'overweight'.

$Z$-scores decreased gradually with increasing age, but there were a few specific changes for each $Z$-score. HAZ was significantly lower than the mean of the criteria during all ages. The lowest HAZ was at age 36-41 months, and the next lowest was at age 54-59 months. WAZ was close to the criteria in the first 6 months, then fell rapidly and remained at a lower level until 60 months. BMIZ was a new indicator in the new WHO standards, added to the previously available set of indicators in the NCHS reference. We found in all age groups, except for 54-59 months, that BMIZ was higher than the WHO standards (Fig. 2).

\section{Malnutrition of children under 5 years old}

Table 3 depicts the prevalence of underweight, stunting and wasting overall and in the different provinces. The overall prevalence of stunting was 30.2\% (95\% CI 29.22, $31 \cdot 27 \%$ ), with the highest prevalence in Tibet (49.5\%) and the lowest in Shaanxi $(7 \cdot 8 \%)$. The overall prevalence of underweight was $10 \cdot 2 \%$ (95\% CI 9.54, 10.89\%), with the highest rate in Tibet (28.7\%) and the lowest in Shanxi (1.9\%). The overall wasting prevalence was $2.9 \%(95 \%$ CI $2 \cdot 51,3 \cdot 25 \%$ ), with the highest rate in Tibet $(6 \cdot 4 \%)$ and the lowest in Chongqing $(0 \cdot 9 \%)$. Table 3 shows that the prevalence of stunting was about three times the prevalence of underweight and more than ten times that of wasting. The rates varied greatly between the different areas (provinces).

Table 1 shows the prevalence of stunting, underweight and wasting by age group. Stunting prevalence was

Table 2 Mean Z-scores of height-for-age (HAZ), weight-for-age (WAZ), weight-for-height (WHZ) and BMI-for-age (BMIZ), determined using the 2006 WHO Child Growth Standards, by age group: children $<5$ years of age from thirteen rural mid-western provinces, China ( $n$ 8041)

\begin{tabular}{|c|c|c|c|c|c|c|c|c|}
\hline \multirow[b]{2}{*}{ Age (months) } & \multicolumn{2}{|c|}{$\mathrm{HAZ}$} & \multicolumn{2}{|c|}{ WAZ } & \multicolumn{2}{|c|}{ WHZ } & \multicolumn{2}{|c|}{ BMIZ } \\
\hline & Mean & SD & Mean & SD & Mean & SD & Mean & SD \\
\hline $0-5$ & -0.47 & 2.06 & 0.04 & $1 \cdot 39$ & 0.67 & $1 \cdot 86$ & 0.46 & $1 \cdot 71$ \\
\hline $6-11$ & -0.66 & $1 \cdot 62$ & -0.33 & $1 \cdot 23$ & $0 \cdot 10$ & $1 \cdot 34$ & 0.07 & $1 \cdot 36$ \\
\hline $12-17$ & $-1 \cdot 16$ & $1 \cdot 37$ & -0.63 & 1.08 & $-0 \cdot 10$ & $1 \cdot 22$ & 0.09 & $1 \cdot 28$ \\
\hline $18-23$ & $-1 \cdot 60$ & $1 \cdot 61$ & -0.73 & $1 \cdot 14$ & 0.13 & 1.57 & 0.41 & 1.59 \\
\hline $24-29$ & $-1 \cdot 56$ & $1 \cdot 23$ & -0.82 & 0.99 & 0.01 & $1 \cdot 02$ & 0.25 & $1 \cdot 11$ \\
\hline $30-35$ & -1.59 & $1 \cdot 36$ & -0.85 & 0.97 & 0.06 & 1.00 & 0.27 & 1.09 \\
\hline $36-41$ & $-1 \cdot 76$ & $1 \cdot 24$ & -0.96 & 0.92 & 0.01 & 1.04 & 0.27 & $1 \cdot 29$ \\
\hline $42-47$ & $-1 \cdot 56$ & $1 \cdot 23$ & -0.94 & 0.91 & -0.03 & 1.02 & $0 \cdot 11$ & 1.05 \\
\hline $48-53$ & $-1 \cdot 62$ & 1.42 & -0.95 & 0.89 & 0.07 & 1.04 & $0 \cdot 19$ & $1 \cdot 22$ \\
\hline $54-59$ & $-1 \cdot 67$ & $1 \cdot 37$ & $-1 \cdot 17$ & 0.92 & $-0 \cdot 19$ & $1 \cdot 11$ & $-0 \cdot 12$ & $1 \cdot 19$ \\
\hline Total & $-1 \cdot 33$ & 1.52 & -0.70 & $1 \cdot 11$ & 0.06 & $1 \cdot 27$ & 0.20 & 1.32 \\
\hline
\end{tabular}

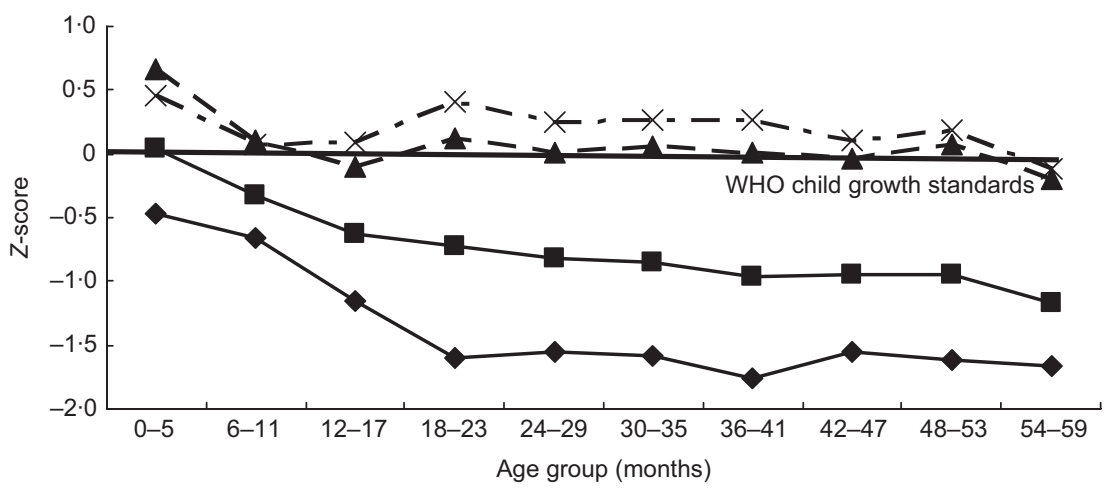

Fig. 2 Z-scores of height-for-age $(-\downarrow-)$, weight-for-age $(-\mathbf{\square}-)$, weight-for-height $(--\mathbf{\Delta}--)$ and BMI-for-age $(--\times--)$, determined using the 2006 WHO Child Growth Standards, by age group: children $<5$ years of age from thirteen rural mid-western provinces, China 
Table 3 Prevalence of underweight, stunting and wasting, determined using the 2006 WHO Child Growth Standards, by province: children $<5$ years of age from thirteen rural mid-western provinces, China ( $n$ 8041)

\begin{tabular}{lccrc}
\hline Province & Sample size & Stunting (\%) & Underweight (\%) & Wasting (\%) \\
\hline Gansu & 611 & $17 \cdot 4$ & $4 \cdot 8$ & $2 \cdot 6$ \\
Qinghai & 820 & $36 \cdot 1$ & $15 \cdot 0$ & $8 \cdot 5$ \\
Jiangxi & 395 & $18 \cdot 1$ & $10 \cdot 3$ & $2 \cdot 8$ \\
Xinjiang & 748 & $28 \cdot 9$ & $9 \cdot 2$ & $2 \cdot 4$ \\
Chongqing & 547 & $40 \cdot 8$ & $11 \cdot 5$ & $0 \cdot 9$ \\
Sichuan & 708 & $35 \cdot 7$ & $12 \cdot 2$ & $3 \cdot 8$ \\
Guizhou & 826 & $42 \cdot 8$ & $15 \cdot 5$ & $3 \cdot 5$ \\
Guangxi & 584 & $39 \cdot 1$ & $1 \cdot 9$ & $3 \cdot 0$ \\
Shaanxi & 558 & $7 \cdot 8$ & $4 \cdot 4$ & $3 \cdot 0$ \\
Inner Mongolia & 407 & $15 \cdot 0$ & $5 \cdot 2$ & $2 \cdot 0$ \\
Shanxi & 515 & $10 \cdot 8$ & $28 \cdot 7$ & $9 \cdot 0$ \\
Tibet & 461 & $49 \cdot 5$ & $9 \cdot 8$ & $2 \cdot 2$ \\
Ningxia & 861 & $19 \cdot 5$ & $10 \cdot 2$ & $2 \cdot 9$ \\
Total & 8041 & $30 \cdot 2$ & & \\
\hline
\end{tabular}

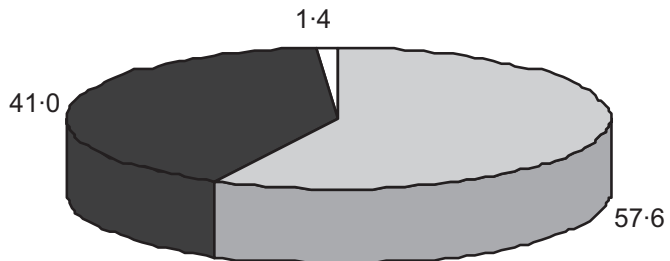

Fig. 3 Percentage with height-for-age Z-score $(H A Z)<-2(\square)$, with $-2 \leq \mathrm{HAZ} \leq 2(\square)$ and with $\mathrm{HAZ}>2(\square)$, determined using the 2006 WHO Child Growth Standards, among the children with overweight from thirteen rural mid-western provinces, China

higher than that of underweight and wasting over the whole age range of $0-59$ months, with a straight rise at age 18-23 months and remaining at a high level until 59 months. The prevalence of wasting was much lower, the lowest value being $0 \cdot 7 \%$ at age $48-53$ months and the highest $4 \cdot 8 \%$ at age $6-11$ months. The increase in the prevalence of underweight was higher than that of wasting, but was lower than that of stunting. Again, all of these observations indicate that stunting was the most important problem for children aged $<5$ years.

Boys had a higher prevalence of stunting, underweight, wasting and malnutrition than girls, but the differences were not significantly significant except for stunting (Table 1).

\section{Wasting and 'overweight'}

Stunting, underweight and wasting are the three most important indices of malnutrition, but in the present study the prevalence of wasting was very low $(2 \cdot 9 \%)$ and quite different from the two other indices. On the contrary, among the 8401 children, 435 had BMIZ $>2$, indicating a prevalence of overweight of $5.4 \%$. The possible risk of overweight (BMIZ>1) was as high as $15 \cdot 2 \%$. Remarkably, it seemed that more children were 'overweight' than 'wasted'.

Have the children in poor areas actually become 'overweight'? We further analysed the relationship between BMI-for-age (BMIZ) and length/height-for-age (HAZ). The results showed that among the 453 children with overweight, the percentage of stunting ( $\mathrm{HAZ}<-2)$ was $57 \cdot 6 \%$, the percentage with $-2 \leq \mathrm{HAZ} \leq 2$ was $41 \cdot 0 \%$, and the percentage of HAZ $>2$ was only $1 \cdot 4 \%$. This indicated that more children were 'stunting overweight', not really 'overweight' (Fig. 3).

\section{Comparison of the WHO standards and the NCHS reference}

The present study is one of only very few, large-scale surveys so far that have used the WHO standards to estimate malnutrition of children. Table 4 illustrates the differences between the new WHO standards and the old NHCS reference.

The overall prevalence of stunting was $21.9 \%$ by the NCHS reference and $30 \cdot 2 \%$ by the WHO standards (Table 4). The prevalence of underweight by the NCHS reference was higher than that by the WHO standards, except for the group aged $0-5$ months. The overall underweight prevalence was $12 \cdot 7 \%$ by the NCHS reference and $10 \cdot 2 \%$ by the WHO standards.

\section{Discussion}

\section{The causes of stunting}

With the WHO standards, we found in the rural communities in our survey that the prevalence of stunting in children $<5$ years old was as high as $30 \%$. Stunting highly influences child health, not only decreasing resistance to diseases such as pneumonia and diarrhoea, but also leading to poor recovery, high fatality rate and many other serious consequences ${ }^{(19-23)}$. In addition, stunting is a high risk factor for adult obesity ${ }^{(24)}$.

One major cause of stunting is long-term energyprotein deficiency. In our survey, 18.5\% infants aged 0-5 months were stunted. Infants at this early stage depend mainly on breast-feeding; therefore stunting at this age is likely to be due to malnutrition of the mother during 
Table 4 Comparison of underweight, stunting and wasting prevalence, determined using the 2006 WHO Child Growth Standards ('WHO standards') and the National Center for Health Statistics/WHO international growth reference ('NCHS reference'), by age group: children $<5$ years of age from thirteen rural mid-western provinces, China ( $n$ 8041)

\begin{tabular}{|c|c|c|c|c|c|c|}
\hline \multirow[b]{2}{*}{ Age (months) } & \multicolumn{2}{|c|}{ Stunting (\%) } & \multicolumn{2}{|c|}{ Underweight (\%) } & \multicolumn{2}{|c|}{ Wasting (\%) } \\
\hline & WHO standards & $\mathrm{NCHS}$ reference & WHO standards & $\mathrm{NCHS}$ reference & WHO standards & $\mathrm{NCHS}$ reference \\
\hline $0-5$ & $18 \cdot 5$ & $7 \cdot 7$ & $4 \cdot 2$ & 0.4 & $3 \cdot 1$ & 0.9 \\
\hline $6-11$ & $17 \cdot 9$ & $10 \cdot 9$ & $8 \cdot 6$ & $8 \cdot 0$ & 4.9 & $3 \cdot 1$ \\
\hline $12-17$ & $22 \cdot 3$ & $17 \cdot 5$ & $7 \cdot 2$ & $13 \cdot 4$ & $4 \cdot 8$ & $5 \cdot 8$ \\
\hline $18-23$ & $35 \cdot 9$ & $30 \cdot 2$ & $12 \cdot 0$ & $17 \cdot 1$ & $2 \cdot 0$ & $4 \cdot 2$ \\
\hline $24-29$ & $34 \cdot 6$ & $17 \cdot 3$ & $10 \cdot 1$ & $14 \cdot 5$ & $1 \cdot 2$ & $2 \cdot 3$ \\
\hline 30-35 & $36 \cdot 5$ & $23 \cdot 4$ & $9 \cdot 5$ & $12 \cdot 8$ & $1 \cdot 6$ & $1 \cdot 6$ \\
\hline $36-41$ & 35.9 & $27 \cdot 2$ & $12 \cdot 6$ & $14 \cdot 8$ & $3 \cdot 0$ & $2 \cdot 2$ \\
\hline $42-47$ & $37 \cdot 1$ & $30 \cdot 0$ & $11 \cdot 2$ & $12 \cdot 0$ & $2 \cdot 2$ & $1 \cdot \overline{7}$ \\
\hline $48-53$ & $32 \cdot 2$ & $29 \cdot 2$ & $11 \cdot 1$ & $12 \cdot 3$ & $0 \cdot 7$ & 0.4 \\
\hline $54-59$ & $39 \cdot 2$ & $36 \cdot 0$ & $19 \cdot 2$ & $19 \cdot 8$ & $4 \cdot 0$ & $2 \cdot 7$ \\
\hline Total & $30 \cdot 2$ & $21 \cdot 9$ & $10 \cdot 2$ & $12 \cdot 7$ & $2 \cdot 9$ & $2 \cdot 8$ \\
\hline
\end{tabular}

pregnancy and the lactation period, indicating that the way to reduce infant stunting is to improve the nutrition of mothers during pregnancy and lactation. From 6 to 59 months stunting rates were very high, especially from 18 months onwards, showing that deficiency of energy and protein intake starts early. Cereals are the principal dietary component in rural areas of mid-western China and are the most important energy source for children. With recent economic development, most rural areas including the mid-western part of China have the capacity to improve infant and child feeding ${ }^{(25)}$, but some misconceptions, such as 'Being difficult to digest, children should not eat meat and egg', still widely exist in these areas, which could contribute to low protein intake among the children. In addition, rising prices could limit caregivers' ability to buy protein-containing foods for their children. We believe that the best way of improving child growth and development is timely, adequate and suitable feeding during the weaning period, especially when it comes to protein and other nutrients such as $\mathrm{Zn}$ and $\mathrm{Fe}^{(26,27)}$. In the running project, health education is one of the important components, and various health education methods will be adopted. We suggest that knowledge about nutrition, especially child feeding, should be a major component in this education, especially in the light of our findings.

\section{'Stunting overweight' but not 'overweight'}

The results from our survey showed that the prevalence of wasting was comparably low and that of 'overweight' was quite high, but further analysis found that the high rate of 'overweight' was a false impression. Consequently, there is a need to increase protein and other nutrients in the diet at an early age, which would change 'stunting', but not to decrease energy intake to avoid 'overweight' alone. We argue that this kind of 'overweight' should be called 'stunting overweight' ${ }^{(5)}$, and is a major and probably growing public health problem that should be given due attention to by the authorities in China.

\section{The WHO standards and NCHS reference}

Until 2006, child growth and development was evaluated by the NCHS reference. The WHO standards were completed in 2006. Compared with the NCHS reference, the WHO standards have two prominent characteristics. The first is that they are based on healthy breast-fed children, and the second that they were developed by MGRS, which was a population-based study including children from different countries and areas ${ }^{(13,17)}$. Therefore it would be more appropriate to assess the nutritional status of children in relation to the new and more universal standards.

Our survey was one of the few studies that so far have used these standards ${ }^{(15,28)}$. Hence we also analysed our data in relation to the older and widely used NCHS reference. The results indicate that with the WHO standards the cut-off point of the $Z$-score for stunting had increased, while the limit for underweight had decreased, which led to a higher prevalence of stunting and a lower prevalence of underweight. This result was similar to the analysis done by $\mathrm{WHO}^{(28)}$. Based on the NCHS reference, the same trends of stunting and underweight prevalence at different months of age were found in the present survey as in the China Nutrition and Health Survey in 2002. The prevalence of stunting and underweight was $21.9 \%$ and $12.7 \%$ respectively in the current survey if the NCHS reference was used; corresponding values in rural areas from the China Nutrition and Health Survey in 2002 were $17 \cdot 3 \%$ and $9 \cdot 3 \%{ }^{(29)}$.

\section{Conclusion}

The 'Mother and Baby Package Project' intervention covers more than one million children $<5$ years of age in mid-western China from 2006 to 2010. The baseline survey found that stunting was as high as $30 \cdot 2 \%$ and was the most serious problem impeding child growth and development. In addition, we found a new phenomenon: the 
high 'overweight' rate in poor areas. On further analysis we definitely indicated this kind of 'overweight' was 'stunting overweight', and the way to solve it should be to increase protein and other nutrients early, and possibly even to pregnant women, but not to decrease energy intake alone. These results constitute very useful information and should also be taken into account for the ongoing project.

\section{Acknowledgements}

Sources of funding: This study was supported/funded by UNICEF and the Chinese Ministry of Health. Conflicts of interest: None declared. Author contributions: X.W. conceived and designed the paper and led the writing; B.H. led the revision of the manuscript and especially edited the paper for language; S.G. designed the study; S.L. designed the study and managed analysis data; W.Z. performed analysis and writing; Y.W. supervised and designed the study. Acknowledgements: We are grateful to Dr Koen Vanormelingen of UNICEF for his support in study concept and design, Messrs Bin Cao and Deying Zhang of the Chinese Ministry of Health for administration of all field process, Mr Bohua Li for statistical advice, and Dr Jingxiong Jiang, Ms Lijuan Li, Ms Huisan Wang, Ms Bo Hao and Ms Gengli Hao for revising the study concept. We also thank Professor Lin An, Professor Jingxu Zhang, Dr Yanqiu Gao, Dr Zhenghong Ren, Ms Ping Duan, Dr Haijun Wang, Dr Chuyun Kang, Professor Xiaolixun Chen, Ms Yuanyuan Wang, Ms Peng Liu, Ms Suizan Zhou, Ms Yuguang Hu, Ms Haihong He, Ms Wenjun Ma, Ms Zhilan Li, Professor Lirong Ju and Professor Li Yang for their help in obtaining data. We extend our gratitude to the thirteen provinces (Gansu, Qinghai, Jiangxi, Xinjiang, Chongqing, Sichuan, Guizhou, Guangxi, Shaanxi, Inner Mongolia, Shanxi, Tibet and Ningxia) and the fifty counties (Jingning, Linzhao, Yongdeng, Linchuan, Anyuan, Huangyuan, Minhe, Huzhu, Guide, Nileke, Xinyuan, Pishan, Shache, Kaixian, Chengkou, Bishan, Cangxi, Pingchang, Muchuan, Xuanhan, Pingguo, Napo, Gongcheng, Lusai, Huguan, Hunyuan, Xiaxian, Mixian, Yuyang, Zhenan, Chayouhouqi, Keerxinzhongqi, Dawaer, Huangping, Congjiang, Panxian, Tongren, Pingtang, Xixiu, Lazi, Jiangzi, Kangma, Chaya, Jiacha, Cuomei, Shenzha, Haiyuan, Xiji, Yuanzhou and Jingyuan) for their support in the field work.

\section{References}

1. Zhai F, He Y, Wang Z, Yu W, Hu Y \& Yang X (2005) The status and trends of dietary nutrients intake of Chinese population. Acta Nutr Sinica 27, 181-184.

2. Min L \& Yun D (2002) The factor leading the difference between west and east in China. Soc Sci Res 2, 46-49.

3. Yang $\mathrm{T}$ (2001) The comparison of economical index between west and east. West China Dev 12, 54-56.

4. National Bureau of Statistics of China (2006) China Statistics Yearbook. http://www.stats.gov.cn/tjsj/ndsj/2006/indexch. htm (accessed May 2008).
5. Chang S, He W \& Chen C (2006) The growth characteristics of children under 5 in the past 15 years. J Hyg Res 35, 768-771.

6. Zeng L, Yan H, Guo X, Dang S \& Xie H (2003) Analysis on malnutrition of children under 3 years old in 40 poor counties in the western areas of China. Chin J Public Health 19, 55-58.

7. Dibley M, Goldsby J, Staehling N \& Trowbridge F (1987) Development of normalized curves for the international growth reference: historical and technical considerations. Am J Clin Nutr 46, 736-748.

8. de Onis M \& Yip R (1996) The WHO growth chart: historical considerations and current scientific issues. Bibl Nutr Diet 53, 74-89.

9. de Onis M \& Habicht JP (1996) Anthropometric reference data for international use: recommendations from a World Health Organization Expert Committee. Am J Clin Nutr 64, 650-658.

10. WHO Working Group on Infant Growth (1994) An Evaluation of Infant Growth. Geneva: WHO.

11. World Health Organization (1994) Infant and Young Child Nutrition. World Health Assembly Resolution WHA47.5. Geneva: WHO.

12. de Onis M, Garza C \& Habicht JP (1997) Time for a new growth reference. Pediatrics 100, 888-889.

13. WHO Multicentre Growth Reference Study Group (2006) WHO Child Growth Standards: Length/height-for-age, weight-for-age, weight-for-length, weight-for-height and body mass index-for-age: Methods and development. Geneva: WHO.

14. Deshmukh PR, Dongre AR, Gupta SS \& Garg BS (2007) Newly developed WHO growth standards: implications for demographic surveys and child health programs. Indian J Pediatr 74, 987-990.

15. Nuruddin R, Lim MK, Hadden WC \& Azam I (2009) Comparison of estimates of under-nutrition for pre-school rural Pakistani children based on the WHO standard and the National Center for Health Statistics (NCHS) reference. Public Health Nutr 12, 716-722.

16. Lohman TG, Roche AF \& Martorell R (1991) Anthropometric Standardization Reference Manual (Abridged Edition). Champaign, IL: Human Kinetics Books.

17. World Health Organization (2006) Training Course on Child Growth Assessment. Version 1 - November 2006. Geneva: WHO

18. Cole TJ, Bellizzi MC, Flegal KM \& Dietz WH (2000) Establishing a standard definition for child overweight and obesity worldwide: international survey. BMJ 320, $1240-1243$.

19. Lutter CK (2003) Meeting the challenge to improve complementary feeding. SCN News 27, 4-9.

20. Pelletier DL, Frongillo EA Jr \& Habicht J-P (1993) Epidemiologic evidence for a potentiating effect of malnutrition on child mortality. Am J Public Health 83, $1130-1133$.

21. Jones G, Steketee RW, Black RE, Bhutta ZA \& Morris SS; Bellagio Child Survival Study Group (2003) How many child deaths can we prevent this year? Lancet 362, 65-71.

22. Pelletier DL, Frongillo Jr EA, Schroeder DG \& Habicht JP (1995) The effects of malnutrition on child mortality in developing counties. Bull World Health Organ 73, 443-448.

23. Pelletier DL (1994) The potentiating effects of malnutrition on child mortality: epidemiologic evidence and policy implications. Nutr Rev 52, 409-415.

24. McCarthy M (1997) Stunted children are at high risk of later obesity. Lancet 349, 34 .

25. Chen C (1995) Eating patterns: a prognosis for China. Asia Pacific J Clin Nutr 4, Suppl., 24-28. 
26. Brown KH, Peerson JM, Rivera J \& Allen LH (2002) Effect of supplemental zinc on the growth and serum zinc concentrations of prepubertal children: meta-analysis of randomized controlled trials. Am J Clin Nutr 75, 1062-1071.

27. Lind T, Lönnerdal B, Stenlund H, Ismail D, Seswandhana R, Ekström EC \& Persson LA (2003) A community-based randomized controlled trial of iron and zinc supplementation in Indonesian infants: interactions between iron and zinc. Am J Clin Nutr 77, 883-890.
28. de Onis M, Onyango AW, Borghi E, Garza C \& Yang H (2006) Comparison of the World Health Organization (WHO) Child Growth Standards and the National Center for Health Statistics/WHO international growth reference: implications for child health programmes. Public Health Nutr 9, 942-947.

29. Yang X, Wang Z, He Y, Yu W, Hu Y \& Zhai F (2005) Trend and prevalence of malnutrition among Chinese children under 5 years old. Acta Nutr Sinica 27, 185-188. 